\title{
Behavioral Ethics and the Incidence of Foodborne Illness Outbreaks
}

\author{
Harvey S. James Jr. ${ }^{1}$ D . Michelle S. Segovia ${ }^{1} \mathbb{D}$
}

Accepted: 3 November 2020 / Published online: 16 November 2020

(c) Springer Nature B.V. 2020

\begin{abstract}
Cognitive biases play an important role in creating and perpetuating problems that lead to foodborne illness outbreaks. By using insights from behavioral ethics, we argue that sometimes people engage in unethical behavior that increases the likelihood of foodborne illness outbreaks without necessarily intending to or being consciously aware of it. We demonstrate these insights in an analysis of the 2011 Listeriosis outbreak in the U.S. from the consumption of contaminated cantaloupes. We then provide policy implications that can improve our understanding of other kinds of disease outbreaks and epidemics.
\end{abstract}

Keywords Food safety $\cdot$ Foodborne illness outbreaks $\cdot$ Cognitive biases $\cdot$ Behavioral ethics

\section{Introduction}

Foodborne illnesses occur when individuals eat foods contaminated with harmful germs, viruses and other microorganisms. According to the U.S. Centers for Disease Control and Prevention (CDC), nearly one in six people in the U.S. get sick each year from a foodborne illness, resulting in more than 100,000 hospitalizations and 3000 deaths (CDC 2020a). The World Health Organization (WHO) reports that globally about one out of every 10 people fall ill to a foodborne illness annually. There are also 420,000 deaths each year around the world, and children under the age of five comprise $40 \%$ of this total (WHO 2020). The social and economic impacts of foodborne illness outbreaks are severe. In addition to straining limited healthcare resources, foodborne illnesses result in lost productivity and employment opportunities, especially in developing countries.

Harvey S. James Jr.

hjames@missouri.edu

Michelle S. Segovia

segoviam@missouri.edu

1 Division of Applied Social Sciences, University of Missouri, Columbia, MO 65211, USA 
As noted by the World Bank (2018, n.p.), “The total productivity loss associated with foodborne disease in low- and middle-income countries is estimated to cost $\$ 95.2$ billion per year, and the annual cost of treating foodborne illnesses is estimated at $\$ 15$ billion." The WHO (2020, n.p.) states that "unsafe food creates a vicious cycle of diarrhoea and malnutrition, threatening the nutritional status of the most vulnerable."

While effective food safety handling techniques by consumers can reduce the incidence of foodborne illnesses caused by contaminated food (WHO 2020), the management practices of farmers and food processors are also important. This is why the WHO (2012) created a report directed at food producers outlining "five keys to growing safer fruits and vegetables." The reason is that contamination at the point where food is produced or distributed can lead to a foodborne illness outbreak. A foodborne illness outbreak occurs "when two or more people get the same illness from the same contaminated food or drink" (FDA 2020).

Foodborne illness outbreaks are a growing problem in the contemporary food system, which is why the WHO (2020) called food safety a "public health priority." For example, in the U.S., the number of investigations conducted by the Food and Drug Administration (FDA), including follow-up investigations to outbreaks occurring in previous years, increased from four in 2011 to 16 in 2019 (FDA 2020). Because over half of the foodborne illness outbreaks are due to contaminated equipment, poor handling practices, and contaminated irrigation water (Onyango et al. 2007; Ranagek et al. 2005), virtually all investigations by the FDA link the source of an outbreak to a farm or food processing company or to a specific growing region. For example, the multistate outbreak of E. coli O157:H7 in 2018 was linked to the consumption of romaine lettuce grown in farms in "three specific California counties" (FDA 2019), while the outbreak of Listeriosis in 2011 that resulted in 33 deaths was linked to the consumption of cantaloupes produced in a single farm in Colorado (FDA 2017). Similar results are observed in other parts of the world. For example, the Listeriosis outbreak in South Africa in 2017-2018 that led to more than 200 deaths was linked to a single producer of processed meats (de Wet 2018). In Germany, an E. coli O104:H4 outbreak that resulted in 53 deaths was linked to the production of fresh seed sprouts by an organic farm in Lower Saxony (HSPH 2012).

In the U.S., there have been numerous efforts to mitigate the incidence of foodborne illness outbreaks, including the introduction of new regulations, such as the Food Safety Modernization Act (Taylor 2011), the recommendations of improved food handling practices (Reynolds and Dolasinski 2019), the reliance on enhanced risk communication practices (Wall and Chen 2018), the education of the public (Wang et al. 2020), and the introduction of new technologies (Hoelzer et al. 2018). Globally, the World Health Organization seeks to promote safe food handling practices of people within its member states (WHO 2020). However, educational and similar efforts often do not produce the behavioral changes in people needed to reduce the incidence of foodborne illness outbreaks (Lee et al. 2017; Reynolds and Dolasinski 2019). Moreover, instead of reducing the incidence of foodborne illness outbreaks, some technologies may actually foster them (DeLind and Howard 2008; Stuart and Worosz 2013). Public regulations and even private standards, while well intended, have proven ineffective as well (Halabi and Lin 2017). Hence, as shown 


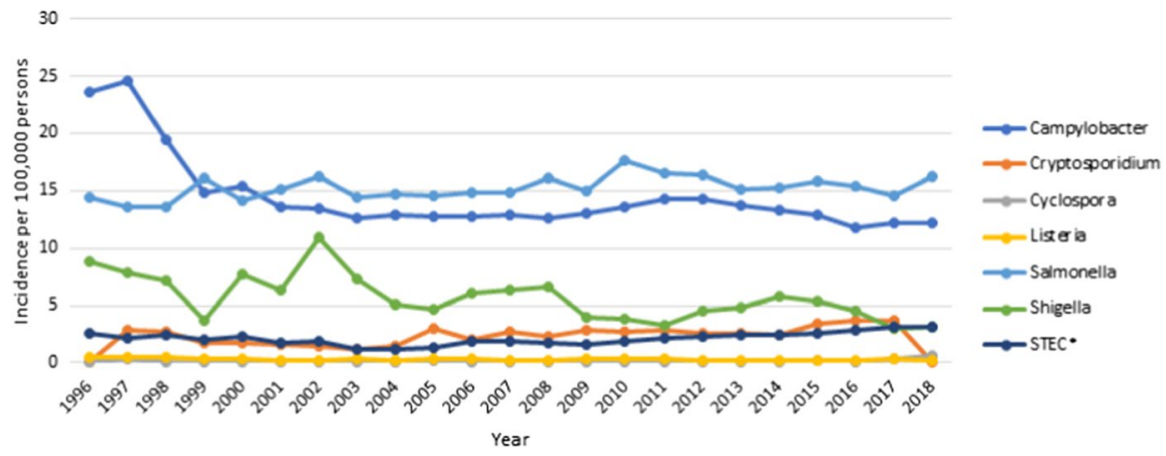

Fig. 1 Incidence of confirmed infections by year. *Shiga toxin-producing Escherichia coli. Source: CDC (2020b)

in Fig. 1 for the case of the U.S., the incidence of confirmed infections by year has remained largely unchanged.

A significant body of research has sought to understand the antecedents and consequences of foodborne illness outbreaks, and to assess the viability of either proposed or implemented solutions. In this regard, scholars have considered issues related to governance of the food system (Konefal et al. 2005; Powell et al. 2013; Green and Kane 2014; Laforge et al. 2017), cultural aspects of food production and consumption (Powell et al. 2011; De Boeck et al. 2016; Baur et al. 2017), and the scale and design of the agricultural system (Parker et al. 2012; Stuart and Worosz 2012; Marine et al. 2016). For example, DeLind and Howard (2008) use the case of the 2006 outbreak of E. coli O157:H7 linked to the sale of bagged spinach from California to show that proposed safety regulations and technologies to combat foodborne illness outbreaks tend to favor large-scale producers at the expense of small-scale producers. This demonstrates that the solutions can "ultimately reinforce the very problems they purportedly address" (p. 312). Other work has illustrated how strategic industrial designs (such as largescale, concentrated, and high-speed production systems) and resistance to production changes (particularly those that do not enhance efficiency or profitability) have resulted in widespread outbreaks (Stuart and Worosz 2012). One proposed solution to outbreaks relates to cultural aspects within organizations and across the food supply chain. For example, Powell et al. (2011) provide examples of outbreaks that could have been prevented if a food safety culture was conveyed through open and transparent communication strategies among producers, processors, and retailers. Examples include the 2008 outbreak of Listeriosis linked to deli meats produced by Maple Leaf Foods, Inc of Canada, and the 2009 outbreak of Salmonella serotype Typhimurium linked to the consumption of peanut products. ${ }^{1}$ This relates to the need of reinforcement of a system of risk based

\footnotetext{
${ }^{1}$ The 1993 Jack in the Box E. coli outbreak originating from contaminated beef patties provides an example of food safety culture as a solution to a foodborne illness outbreak. After the incident, the company completely restructured their corporate operations around food safety priorities (e.g., microbial testing every $15 \mathrm{~min}$, use of a checklist for slaughterhouses and transportation temperatures), setting new standards across the fast food industry (Andrews 2013).
} 
food safety management rather than the use of traditional 'snap-shot' inspections, solution proposed by Green and Kane (2014).

An emerging literature in "the area of food safety ethics" (Sperling 2010) suggests that the cognitive, moral and behavioral aspects of decision-makers may also influence the effectiveness of the agrifood system (Ferrari et al. 2019). For example, Stuart and Worosz (2012) show how entrenched interest groups, such as industry organizations, fail to reflexively assess their actions and consciously adopt "techniques to convince themselves or others that their actions do not constitute unethical behavior" (p. 295). Similarly, Ge and Brewster (2016, p. 73) argue that the rapid growth of available technologies adopted by agents in the agrifood sector not only increases the amount of information available, but also creates "a new form of ignorance ('meta-ignorance') that diminishes the effectiveness of information on decision-makers" because of limitations in the cognitive capacity of people. In other words, too much or too little information can create problems for decision-makers.

We build on this developing perspective by suggesting that an important reason for a lack of progress in reducing the incidence of foodborne illness outbreaks is that epidemiologists, policymakers, scientists and academics overlook the role cognitive biases have in perpetuating problems that lead to foodborne illness outbreaks. Our argument, which derives from the field of behavioral ethics (see Bazerman and Gino 2012; Bowman 2018), is that cognitive biases interfere with the decision-making process of actors in the food system. In contrast to scholars who note that agents in the food system may not be concerened about the risks of contracting or spreading foodborne illness diseases (e.g., Young and Waddell 2016), or those who suggest that foodborne illness outbreaks are tied to conscious unethical decisions made by agents (e.g., Stuart and Worosz 2012), we argue that decision-makers may be unaware that their actions are unethical or problematic and thus can unintentionally create food safety problems. Thus, in this paper, we consider how cognitive biases create and perpetuate problems that lead to foodborne illness outbreaks. While researchers have recognized a role that cognitive biases play in the problem of foodborne illness outbreaks, most focus on the perspective of consumers (e.g., Shan et al. 2019) and policymakers (e.g., Jacobs 2009). A few studies recognize that cognitive biases of food safety handlers can affect the incidence of foodborne disease outbreaks (e.g., Gomes de Freitas et al. 2019). However, we argue that a more systematic assessment of the cognitive biases of decision-makers across the entire agrifood supply chain is needed if we are to see genuine progress.

In this paper we provide insight into how cognitive biases can contribute to the persistent problem of foodborne illness outbreaks by drawing on principles from behavioral ethics. To give the discussion substance, we conduct a case study analysis of the 2011 Listeriosis outbreak from the consumption of contaminated cantaloupes in the U.S. Lastly, we provide policy implications that can be further apply to other kinds of disease outbreaks and epidemics. The relevance of this paper lies in the crucial though overlooked perspective on why foodborne illnesses represent a perpetual problem. 


\section{Cognitive Biases and Unintentional Unethical Behavior}

For decades, unethical behavior has been studied using the traditional economics approach of Becker (1968). Its central argument is that individuals carry out unethical behaviors in a conscious and deliberate manner by trading off the expected benefits and costs of the dishonest action. In combination with Becker's incentive approach, researchers have considered unethical behavior as deliberate, so they sought to understand why seemingly good people intentionally engage in unethical behavior. For example, people may attempt to justify or rationalize their unethical actions (Bersoff 1999), or they may deny responsibility or refuse to acknowledge injury to others in order to neutralize any adverse psychological effects resulting from their unethical behavior (Sykes and Matza 1957; Vitell and Grove 1987).

Insights from psychology and behavioral decision research, however, suggest that sometimes people engage in unethical behavior without necessarily intending to or being consciously aware of it (Tenbrunsel and Messick 2004; Chugh et al. 2005; Bazerman and Tenbrunsel 2011). In other words, people might engage in behaviors that they would condemn and consider unethical upon further awareness or reflection. This points to the limits of the conscious mind and the importance of cognitive biases and other unconsciously guided acts to explain unethical behavior (Banaji and Bhaskar 2000; Banaji et al. 2003; Chugh et al. 2005; Bazerman and Gino 2012).

Cognitive biases are systematic errors in thinking that cause people to act repeatedly in an irrational way (Tversky and Kahneman 1974; Kahneman and Tversky 1979). Cognitive biases are often the result of people's attempt to rely on simplifying strategies or cognitive heuristics-that is, mental shortcuts or rules of thumb-that enable faster decision-making. The study of cognitive biases has been integral in the development of behavioral ethics.

Behavioral ethics draws on research from social psychology, behavioral economics and neuroscience to understand why people sometimes act in ways that are inconsistent with their ethical beliefs and why people sometimes engage in activities that unintentionally result in unethical outcomes (Gino et al. 2009a; Bazerman and Gino 2012; Bowman 2018). The problem of foodborne outbreaks is an example. While intentional contamination of food and other ingestible products occurs, such as the case in 1982 of Tylenol capsules being laced with potassium cyanide that resulted in the deaths of seven people in Chicago, Illinois (Haberman 2018), most cases of foodborne outbreaks are unintentional (Ma et al. 2017). This paper focuses on the role of unintentional unethical actions on the propagation of foodborne illness and its relation with cognitive biases. How does an understanding of cognitive biases help explain incidents of foodborne outbreaks, and how does this understanding inform on policy formulation to reduce the chance that foodborne outbreaks will occur? We use insights from behavioral ethics to answer these questions. We start by defining unethical behaviors. Unethical behavior means engaging in actions that one knows, feels or believes is wrong or that causes harm to others or to the system as a whole (e.g., Jones 
1991). In the context of food safety, unethical behavior may also include engaging in actions that increase the level of risk consumers face from consuming products when "they can never know for sure that something is safe" (Johnson 1986, p. 171). However, under the premise of behavioral ethics, farmers and food processors may unintentionally engage in activities that they should anticipate are wrong, cause harm, or increase risk to consumers, but they are unaware their actions contribute to these problems because of cognitive biases. Based on this framework, we describe relevant cognitive biases and show how they are manifested in a specific case of foodborne illness outbreak-the Listeriosis outbreak in 2011 linked to the consumption of contaminated cantaloupes. ${ }^{2}$ Our conclusion focuses on policy implications.

\section{Cognitive Biases}

Although there are many cognitive biases, the following are examples that appear to be particularly relevant to the case of foodborne illnesses.

\section{Motivated Blindness}

This bias is rooted in the self-interest of people and arises when individuals face a conflict of interest, or creates one in others, which impairs their ability to judge rationally the ethics of their actions (Moore et al. 2006). The failure of auditor independence provides a good example of motivated blindness (Bazerman and Moore 2011; Bazerman and Tenbrunsel 2011; Bazerman et al. 1997). For many years, auditing firms in the US worked for their clients not only as auditors but also as consultants, engaging in non-audit services that compromised the independence of their audits. These auditor conflicts of interest led to the bankruptcy of big firms such as Enron, WorldCom, and Tyco (Moberg and Romar 2003; Giroux 2008). Although intentional corruption is probable, evidence on unconscious bias suggest that professionals are often unaware of how morally compromised they are by conflicts of interest (Moore et al. 2006).

In the food industry, farmers and food processing companies face significant pressures to remain competitive while balancing the costs of improving food safety handling processes. These pressures can perpetuate a motivated blindness bias that results in decision-makers taking shortcuts or overlooking practices that increase the risk of food contamination. In addition, most food safety audits are conducted by a third-party organization hired at the company's expense (Lytton and McAllister 2014; Powell et al. 2013). Although the outmost result of auditing is the prevention of foodborne illnesses, there have been several foodborne outbreaks associated with food companies that have been successful in third-party audits (Kotsanopoulos

\footnotetext{
2 Although more incidences of foodborne illnesses have been linked to other bacteria such as Salmonella and Campylobacter, we focus on the Listeriosis outbreak linked to cantaloupes as it is considered the deadliest foodborne illness outbreak in over more than 80 years in the U.S. (Flynn 2011).
} 
and Arvanitoyannis 2017; Costa 2010). The 2009 outbreak of Salmonella serotype Typhimurium linked to peanut products manufactured by Peanut Corporation of America (PCA) has been frequently cited as an example of a failure in third-party auditing in the food industry (Moss and Martin 2009; Steir 2009). Despite numerous food safety failures within the organization-e.g., deficiencies in cleaning and sanitization processes, and inadequate handling of contaminated products, PCA had maintained the highest ratings by AIB International prior to the outbreak.

A potential contributor to this issue is the conflict of interest frequently faced by auditors that prevent them to provide negative evaluations and report incidents occurring at the company (Powell et al. 2013). This conflict of interest arises because auditors are paid by the company that they audit and they have a financial interest in getting rehired. A company receiving a poor audit may be unwilling to hire that auditor again which may result in financial losses to the auditor. ${ }^{3}$ Also, auditing companies have no legal authority and are not required to report non-compliances to regulatory agencies (Costa 2011). However, often times, auditors may not understand how social pressures and self-interests can lead them to move away from their moral compass.

\section{Outcome Bias}

Because outcomes are often the result of a confluence of individual decisions made by many people, the outcome bias is manifested when people judge the ethics of a particular action based on the outcome rather than the individual acts producing it (Gino et al. 2009a, 2012). In other words, it arises when a positive outcome mitigates a known unethical process or action creating it. From a rational perspective, judgements of ethical behavior should not depend upon a randomly determined outcome (Hastie and Dawes 2009). However, recent studies have shown that people tend to judge others' behavior as more unethical when they lead to negative outcomes rather than positive outcomes (Cushman et al. 2009; Gino et al. 2009a). Stated differently, if an unethical action does not produce a negative outcome like a foodborne illness outbreak, then those making decisions may not believe or see that they did anything wrong. The presence of outcome biases can help perpetuate a problem of foodborne illnesses, particularly when the company's goal is focused on quantity or quality production outcomes only. This could cause managers and employees to unintentionally ignore poor food handling and processing practices and to tolerate others' unethical decisions over long periods until they result in negative consequences (e.g., food poisoning), even when such consequences can be easily predicted (Watkins and Bazerman 2003).

\footnotetext{
3 See Lytton and McAllister (2014) for a review on conflict of interest in food safety auditing.
} 


\section{Omission Bias}

According to the omission bias, not doing something is seen as less problematic than doing something, even if the outcomes are the same (Tenbrunsel et al. 2010; Tenbrunsel and Messick 2004; Spranca et al. 1991; Ritov and Baron 1990). However, from a moral point of view, committing a harmful or unethical act is not worse than failing to take an action that causes a similar magnitude of harm (Sunstein 2004). Perceiving there is a distinction can cause problems, such as contributing to prolonging foodborne illnesses. For example, an employee of a food processing plant might often observe and ignore poor food processing practices or product adulteration, thus ensuring the adulterated product make it to the market. In another case, an employee might directly participate in the food adulteration activity, making the adulterated product available to consumers. If people have a strong moral intuition that failure to report the company's wrongdoing is acceptable but that being one of the wrongdoers is unacceptable, then they are affected by the omission bias, even though there is no morally relevant difference between the two.

\section{Indirect Bias}

This bias arises when harm caused by delegating is seen as less problematic than harm caused by oneself (Paharia et al. 2009). A bias favoring indirect harms may have implications for how unethical practices in the food industry are punished by our legal system. Acting indirectly through third parties, such as external auditors, can lessen the extent of the company's control over foodborne illnesses caused by poor handling and processing practices. This implies that juries may be biased to evaluate indirect harms less negatively, thus making them less likely to deliver guilty verdicts when harm is committed through a secondary agent. The growing use of third-party certification and private standards of farming and food processing activities (Fouilleux and Loconto 2017), and the persistent belief that government inspections and audits are sufficient to ensure safe food (Powell et al. 2013), perpetuate the ethical challenges created by the indirect bias.

\section{Identifiable Victim Effect}

When people see non-identifiable or statistical victims as less problematic than identifiable or known victims, they are affected by this bias (Loewenstein et al. 2006; Small and Loewenstein 2003, 2005; Kogut and Ritov 2005; Jenni and Loewenstein 1997). Gino et al. (2010) show that people tend to consider others' questionable behavior as more unethical when the victim of wrongdoing is identified than when is not, and that people are more likely to punish unethical behavior in the former case than in the later. This means that customers may punish unethical decisions made by a food company more harshly_for instance, by not purchasing their productswhen the victim is a person they identify with rather than someone they don't know. 
One implication of the identifiable victim effect is that telling people that a specific victim exists increases caring and sympathy, even when identification provides no meaningful information (Small and Loewenstein 2005).

\section{The Case of Recalled Cantaloupes Produced by Jensen Farms in 2011}

We consider now the case of Jensen Farms in Colorado, which was a cantaloupe producer until a Listeriosis outbreak in 2011 linked to the farm resulted in bankruptcy and criminal charges filed against the farm owners. Although this case is primarily descriptive, it is important not only because of the severity of the foodborne illness outbreak but also because intense public scrutiny of the event provide an effective means of showing how cognitive biases might have contributed to behavior resulting in the contamination of the cantaloupe products. In doing so, we acknowledge the speculative nature of our conclusions. However, the evidence presented is consistent with decision-making that could have been affected by various cognitive biases.

In early September 2011, the CDC and FDA began an investigation of a multistate outbreak of Listeriosis. The investigation pointed to cantaloupes produced by Jensen Farms in Granada, Colorado, and shipped between July and September 10. The FDA collected samples from the farm and concluded that most of the infection had originated at the processing line, with additional contamination occurring in the packing area (FDA 2017). For example, the FDA found that "Certain aspects of the packing facility, including the location of a refrigeration unit drain line, allowed for water to pool on the packing facility floor in areas adjacent to packing facility equipment" (FDA 2011, n.p.). On September 12, the CDC reported that 15 people had been infected in four states. However, 2 weeks later, 13 people had died and another 72 had confirmed illnesses (CNN 2011). Grocery stores issued recalls of the fruit beginning the middle of September, but that was not enough to contain the spread of the outbreak. By the end of February, 2012, 147 people had been infected in 28 states, and 33 people had died (CDC 2012).

The outbreak of Listeriosis originating from cantaloupes produced at Jensen Farms is said to be one of the deadliest cases of foodborne illness caused by contaminated food in the US (Allen 2011). ${ }^{4}$ Because of the severity of the health crisis, the US government used provisions in the Food, Drug and Cosmetic Act to bring criminal charges against the owners, Eric and Ryan Jensen. The brothers pled guilty in 2013 to six misdemeanor charges of food adulteration, and aiding and abetting. In 2014, they were sentenced to 5 years probation and 6 months home detention (Marklein 2014).

\footnotetext{
4 The most lethal food illness outbreak was linked to typhoid bacteria in raw oysters, which resulted in 150 deaths in 1924-1925. The second deadliest foodborne illness outbreak is the streptococcus outbreak in 1911 linked to raw (unpasteurized) milk which resulted in 48 deaths (Flynn 2011). The Listeria contamination of processed meats in South Africa, which infected more than 1000 people and caused the death of more than 200 persons, is likely the most lethal foodborne illness outbreak globally (WHO 2018).
} 
The Jensen brothers did not intend to create a foodborne illness outbreak. In fact, after an audit of their cleaning and packing process in 2010, the brothers wanted to improve their food safety efforts (USHR 2012). However, cognitive biases may have unintentionally lead to behaviors that were either unethical or resulted in harmful outcomes. For example, consider the problem of motivated blindness, which focuses on incentives to advance one's self-interest and the failure to take reasonable precautions to avoid conflicts of interest in oneself or others. The Jensen brothers hired a third-party auditor, Primus Group, to provide inspection services of the farm's cleaning and processing equipment. Primus, in turn, subcontracted the inspection to a different auditor, Bio Food Safety (Prevor 2011). While Primus offered several options for stringency and rigor in the auditing services it provided, the Jensen brothers chose the least rigorous audit, "the standards of which conformed to industry custom and government regulations" (Lytton 2019, p. 16), consistent with a cost minimization strategy of operating a business. Furthermore, the hiring of Bio Food Safety created a conflict of interest for Primus, which relies on farming businesses that hire and pay them for their services. This create an incentive for the auditor to be more lenient in their findings in order to ensure future business from the hiring farm and those who associate with the farm. For instance, the Jensen brothers explained changes they made in their cleaning equipment to the auditor, yet "the PrimusLabs subcontractor did not question what they'd done, did not warn them of any risk of contamination, and did not discuss U.S. Food and Drug Administration (FDA) guidelines with them" (Flynn 2013, n.p.). In fact, the auditor gave Jensen Farms a "superior" rating. If the Jensen brothers had recognized the conflict of interest the auditor faced, and if the brother's interests were more directly tied to food safety than farm profitability, then they might have noticed that additional protocols could have been taken to increase the safety of the cleaning and processing facilities. In other words, the business decisions the bothers made to advance their interests are consistent with actions affected by a motivated blindness bias.

To illustrate the outcome bias, we note that a Congressional investigation of the listeria outbreak reported that "Jensen Farms has been in operation for several generations and has grown and packaged cantaloupes for the past 20 years. ... Prior to the Listeria outbreak, Jensen Farms had no reported food safety problems" (USHR 2012 , p. 4). However, an audit in July 2011 of the farm revealed that the brothers did not use an antibacterial wash when they cleaned the cantaloupes, even though they had the equipment to do it. Nevertheless, the auditor gave them a "superior" rating. As a result, according to the report, "The Jensen brothers stated that based on these inspections and their prior food safety record, they had no concerns about their operations prior to the recent outbreak" (USHR 2012, p. 5; emphasis added). While the brothers knew their cantaloupes could be contaminated (USDoJ 2013), the fact that no problems had occurred previously underscored their decision not to use the required chemical wash, consistent with an outcome bias.

As an example of the omission bias, the Jensen brothers did not intentionally contaminate the cantaloupes they produced. Rather, they failed to take actions that could have further reduced the likelihood of contamination, such as using the antibacterial wash. According to their lawyer, "The charges against Eric and Ryan Jensen do not imply that they knew, or even should have known, that the cantaloupes had been 
contaminated" (Long 2013a). The brothers believed they were making their product safer by installing new cleaning equipment and arranging for the required audits of their processing facility. It was the failure to take additional safety actions that ultimately got the brothers in trouble, not a conscious decision to contaminate the food they produced.

In October 2013, the Jensen brothers sued the third-party auditor, Primus Group (Flynn 2013). As illustrated by the indirect bias, the Jensen brothers claimed that the auditor should have observed conditions that would have likely resulted in the improper cleaning and processing of the cantaloupes. Thus, the auditor should bear (at least some) responsibility for the foodborne illness outbreak linked to their farm. According to one commentator, "the Jensens have made clear their belief that they are not the only ones at fault for their personal downfall and the fourth-generation family business' end" (Shapiro 2013). Relying on the advice of external or thirdparty "experts" is, prima facie, an ideal example of the indirect bias.

According to the identifiable victim effect, not knowing the identity of victims can harden one to the human consequences of one's actions, while knowing the identity of victims can change or soften one's assessment of an action. The Jensen brothers met with several victims and their families in November 2013. The meeting seemed to have an effect on the brothers as well as in the way the public judged the brothers. Prior to the meeting, the brothers blamed the third-party auditor for failing to inform them of problems. During the meeting with victims, however, the brothers appeared more willing to accept responsibility by expressing sorrow for the outbreak. As a result, the wife of a man who died from the disease said, "I don't think that they meant to do anything deliberately wrong," while another family member said, "I personally don't think the Jensens are bad people. I think they were led astray. In their heart, I think they know they have done something wrong" (Long 2013b). In other words, identifying, or identifying with, victims can help overcome the bias associated with the identifiable victim effect and produce a genuine act of understanding in people whose actions adversely affect others. ${ }^{5}$

\section{Conclusions}

Cognitive biases can play an important role in creating situations where individuals producing or handling food might inadvertently or unintentionally engage in practices that result in ethically compromising situations, such as the adulteration of food products. Given the seriousness of foodborne illness outbreaks when they arise, and the fact that foodborne illness outbreaks continue to be a problem in spite of considerable efforts to combat them, it is necessary to consider any and all factors that might affect the incidence of contamination of food products. Insights from behavioral ethics, and an understanding of cognitive biases that people face, are a crucial step in this direction. Clearly, more research is needed to explore the connection between cognitive biases and the behavior of people producing and handling

\footnotetext{
5 We thank an anonymous reviewer for making this observation.
} 
food products. For example, while the problem of foodborne illness outbreaks is hardly a new phenomenon, it might be helpful to undertake a review of evidence on the causes of foodborne illness using observational data and reports in order to identify a role cognitive biases and behavioral factors played in perpetuating them. An historical overview of prominent cases of foodborne outbreaks in the last century might be a good starting point, tracing their connection to cognitive biases (as done in this paper) as factors contributing to the problem. Databases and information from entities like the FDA and the WHO would be helpful, we well as scientific studies published in peer-reviewed journals, personal interviews, professional commentary, and the popular press. This examination will allow researchers to review the chain of events connecting food safety scandals or outbreaks to unethical unintended behaviors committed by actors across the food supply chain. Based on this evidence, models explaining the behavior described in the case studies could be formulated, providing improvements in attributing illness to food safety and associated systematic behavioral failures.

Our conclusions have an important implication for other kinds of disease outbreaks and epidemics, such as the recent case of the Coronavirus Disease (COVID19). Cognitive biases play a fundamental role in the way people respond to pandemics and adhere to directives such as social isolation and distancing. For example, motivated blindness and the outcome bias can induce restaurants and food business to ignore lockdown requirements by re-opening in early stages if they face a conflict between meeting their economic needs and following health and public policy, and if they do not see their behavior as directly contributing to someone else getting sick (employees or patrons). Ignoring these biases has caused numerous food services to close after thousands of employees test positive for COVID-19. This also relates to the multiple outbreaks of COVID-19 that happened at meatpacking plants and slaughterhouses in the United States due to the industry's desire to meet the increase in meat demand (McCarthy and Danley 2020). Although protocols have been developed to decrease food safety risks while continuing operations in meat facilities (CDC 2000c), compliance with these protocols and directives depends highly on the employees' willingness to cooperate, which may be problematic under the influence of cognitive biases. Other biases are relevant. A bias known as herding behavior, which arises when people follow the crowd even if they disagree with what others are doing (Raafat et al. 2009), can explain why the food industry experienced large demand spikes on basic staples due to consumers' feeling of urgency to stock up on a small sliver of essentials such as pasta, rice and beans. Herding behavior may be manifested due to people's fear and aversion to welfare losses (because of price increases or food shortages).

Insights from behavioral ethics can also be used to formulate policies that nudge people in directions that promote their economic welfare without reducing their freedom of choice (Thaler and Sunstein 2003). This approach is based on the premise that appropriately designed policy interventions can improve individual's decision-making by reducing errors caused by cognitive biases, thus making each individual better off as measured by their own preferences. Although behavioral insights have been successfully used in various policy programs-for instance, in energy conservation, food waste, and water security (Cadario and Chandon 2020; Bolos 
et al. 2019; Ferraro et al. 2017; Allcott and Rogers 2014; Bernedo et al. 2014; Goldstein et al. 2008)—policymakers have overlooked the benefits that nudges can have in reducing the incidence of foodborne illnesses, as illustrated by the improvement nudges can make in hand hygiene (Caris et al. 2018). In this regard, understanding the consequences that unintentional unethical behavior has on the propagation of foodborne illness outbreaks is vital for formulating policies and designing institutions that secure food safety. For example, ignoring the presence of potential cognitive biases in external auditing can threaten the validity of food quality assessments and protection of the consumer (Powell et al. 2013). Given the fact that companies cannot rely only on external auditing to ensure high quality standards, they can look into behavioral approaches that can increase internal compliance with food safety regulations, including aspects related to reputation, shaming, and social sanctioning. Behavioral ethics scholars have found experimental support for the notion that shaming penalties and social norms can shape preferences against unethical actions (Gino and Galinsky 2012; Gino et al. 2009b; Skeel 2001; Kahan and Posner 1999). Thus, internal adoption of codes of conduct and ethical rules can be enforced by increasing the saliency of people's noncompliance and making punishment common knowledge.

The importance and relevance of cognitive biases should not be overlooked when developing campaigns to reduce foodborne illness outbreaks. At the very least, accepting and understanding their existence represents an opportunity for all participants in the food supply chain-from farmers/producers to consumers-to become more aware of their ethicality and why there might be a gap between their desire to be moral and operate safely and their actual behavior.

Funding This project was supported by Hatch Project Number MO-AC011AC047.

\section{Compliance with Ethical Standards}

Conflict of interest The authors declare they have no conflict of interests.

\section{References}

Allcott, H., \& Rogers, T. (2014). The short-run and long-run effects of behavioral interventions: Experimental evidence from energy conservation. American Economic Review, 104(10), 3003-3037.

Allen, J. E. (2011). Tainted cantaloupes behind deadliest food-borne outbreak. ABC News, November 3. https://abcnews.go.com/Health/Health/cantaloupes-tied-deadliest-food-outbreak/story?id=14874 373\#.TrQcKoReO-o. Accessed 22 April 2020.

Andrews, J. (2013). Jack in the Box and the decline of E. coli. Food Safety News, February 11. https ://www.foodsafetynews.com/2013/02/jack-in-the-box-and-the-decline-of-e-coli/. Accessed 21 July 2020.

Banaji, M. R., Bazerman, M. H., \& Chugh, D. (2003). How (un) ethical are you? Harvard Business Review, December, 3-10.

Banaji, M. R., \& Bhaskar, R. (2000). Implicit stereotypes and memory: The bounded rationality of social beliefs. In D. L. Schacter \& E. Scarry (Eds.), Memory, brain, and belief (pp. 139-175). Cambridge, MA: Harvard University Press. 
Baur, P., Getz, C., \& Sowerwine, J. (2017). Contradictions, consequences and the human toll of food safety culture. Agriculture and Human Values, 34, 713-728.

Bazerman, M. H., \& Gino, F. (2012). Behavioral ethics: Toward a deeper understanding of moral judgment and dishonesty. Annual Review of Law and Social Science, 8, 85-104.

Bazerman, M. H., \& Moore, D. (2011). Is it time for auditor independence yet? Accounting, Organizations and Society, 36(4-5), 310-312.

Bazerman, M. H., Morgan, K. P., \& Loewenstein, G. F. (1997). The impossibility of auditor independence. Sloan Management Review, 38, 89-94.

Bazerman, M. H., \& Tenbrunsel, A. E. (2011). Blind spots: Why we fail to do what's right and what to do about it. Princeton, NJ: Princeton University Press.

Becker, G. S. (1968). Crime and punishment: An economic approach. Journal of Political Economy, 76(2), 169-217.

Bernedo, M., Ferraro, P. J., \& Price, M. (2014). The persistent impacts of norm-based messaging and their implications for water conservation. Journal of Consumer Policy, 37(3), 437-452.

Bersoff, D. M. (1999). Why good people sometimes do bad things: Motivated reasoning and unethical behavior. Personality and Social Psychology Bulletin, 25(1), 28-39.

Bolos, L. A., Lagerkvist, C. J., \& Nayga, R. M. (2019). Consumer choice and food waste. Choices, 34(1), $1-7$.

Bowman, J. S. (2018). Thinking about thinking: beyond decision-making rationalism and the emergence of behavioral ethics. Journal of Public Integrity, 20(S1), S89-S105.

Cadario, R., \& Chandon, P. (2020). Which healthy eating nudges work best? A meta-analysis of field experiments. Marketing Science, 39(3), 465-486.

Caris, M. G., Labuschagne, H. A., Dekker, M., Kramer, M. H. H., van Agtmael, M. A., \& Vandenbroucke-Grauls, C. M. J. E. (2018). Nudging to improve hand hygiene. Journal of Hospital Infection, 98(4), 352-358.

CDC. (2000c). Meat and poultry processing workers and employers. Washington, DC: CDC. https:// www.cdc.gov/coronavirus/2019-ncov/community/organizations/meat-poultry-processing-workersemployers.html. Accessed July 222020.

CDC. (2012). Multistate outbreak of listeriosis linked to whole cantaloupes from Jensen Farms, Colorado (FINAL UPDATE). Washington, DC: CDC. https://www.cdc.gov/listeria/outbreaks/cantaloupe s-jensen-farms/index.html. Accessed 22 April 2020.

CDC. (2020a). Foodborne germs and illnesses. Washington, DC: CDC. https://www.cdc.gov/foodsafety/ foodborne-germs.html. Accessed 22 April 2020.

CDC. (2020b). Pathogen Surveillance. Washington, DC: CDC. https://wwwn.cdc.gov/foodnetfast/. Accessed 22 April 2020.

Chugh, D., Bazerman, M. H., \& Banaji, M. R. (2005). Bounded ethicality as a psychological barrier to recognizing conflicts of interest. In D. A. Moore, D. M. Cain, G. Loewenstein, \& M. H. Bazerman (Eds.), Conflicts of interest: Challenges and solutions in business, law, medicine, and public policy (pp. 74-95). New York: Cambridge University Press.

CNN. (2011). Cantaloupe-related outbreak of illness linked to 13 deaths. CNN, September 29. https:// edition.cnn.com/2011/09/27/health/cantaloupe-deaths/. Accessed 22 April 2020.

Costa, R. (2010). The food safety inspection party. Food Safety and Environmental Health Blog. https ://www.safefoodsblog.com/2010/10/food-safety/the-food-safety-inspection-party/. Accessed 3 July 2021.

Costa, R. (2011). The role of the third-party food safety auditor. Environ Health Associates, Inc. https ://www.safefoodsblog.com/2011/10/farm-to-fork/the-role-of-the-third-party-food-safety-auditor/. Accessed 3 July 2021.

Cushman, F., Dreber, A., Wang, Y., \& Costa, J. (2009). Accidental outcomes guide punishment in a "trembling hand" game. PLoS ONE, 4(8), e6699.

De Boeck, E., Jacxsens, L., Bollaerts, M., Uyttendaele, M., \& Vlerick, P. (2016). Interplay between food safety climate, food safety management system and microbiological hygiene in farm butcheries and affiliated butcher shops. Food Control, 65, 78-91.

de Wet, P. (2018). Tiger Brands' R2.2 billion processed meat business catches fire as listeriosis is traced to its Polokwane facility. Business Insider South Africa, March 4. https://www.businessinsider.co. za/tiger-brands-catches-listeriosis-from-enterprise-2018-3. Accessed 19 October 2020.

DeLind, L. B., \& Howard, P. H. (2008). Safe at any scale? Food scares, food regulation, and scaled alternatives. Agriculture and Human Values, 25, 1-17. 
FDA. (2011). Environmental assessment: Factors potentially contributing to the contamination of fresh whole cantaloupe implicated in a multi-state outbreak of listeriosis. Washington, DC: FDA. https:// www.fda.gov/Food/RecallsOutbreaksEmergencies/Outbreaks/ucm276247.htm. Accessed 22 April 2020.

FDA. (2017). Information on the recalled Jensen Farms whole cantaloupes. Washington, DC: FDA. http://wayback.archive-it.org/7993/20171114155043/https://www.fda.gov/Food/RecallsOutbreak sEmergencies/Outbreaks/ucm272372.htm. Accessed 22 April 2020.

FDA. (2019). Investigation summary: factors potentially contributing to the contamination of romaine lettuce implicated in the fall 2018 multi-state outbreak of e. coli O157:H7. Washington, DC: FDA. https://www.fda.gov/food/outbreaks-foodborne-illness/investigation-summary-factors-potentiall y-contributing-contamination-romaine-lettuce-implicated-fall. Accessed 22 April 2020.

FDA. (2020). Outbreaks of foodborne illness. Washington, DC: FDA. https://www.fda.gov/food/recallsoutbreaks-emergencies/outbreaks-foodborne-illness. Accessed 22 April 2020.

Ferrari, L., Cavaliere, A., De Marchi, E., \& Banterle, A. (2019). Can nudging improve the environmental impact of food supply chain? A systematic review. Trends in Food Science \& Technology, 91, 184-192.

Ferraro, P., Messer, K. D., \& Wu, S. (2017). Applying behavioral insights to improve water security. Choices, 32(4), 1-6.

Flynn, D. (2011). Deadliest U.S. Foodborne illness outbreaks. Food Safety News, November 8. https ://www.foodsafetynews.com/2011/11/a-top-10-list-of-deadliest-foodborne-illness-outbreaks/. Accessed 21 July 2020.

Flynn, D. (2013). Jensen Brothers take responsibility but blame PrimusLabs. Food Safety News, October 21. https://www.foodsafetynews.com/2013/10/jensen-brothers-sue-primus-over-third-party-audit -they-say-was-faulty/. Accessed 29 April 2020.

Fouilleux, E., \& Loconto, A. (2017). Voluntary standards, certification, and accreditation in the global organic agriculture field: a tripartite model of techno-politics. Agriculture and Human Values, 34, $1-14$.

Ge, L., \& Brewster, C. A. (2016). Informational institutions in the agrifood sector: meta-information and meta-governance of environmental sustainability. Current Opinion in Environmental Sustainability, $18,73-81$.

Gino, F., Ayal, S., \& Ariely, D. (2009a). Contagion and differentiation in unethical behavior: The effect of one bad apple on the barrel. Psychological Science, 20(3), 393-398.

Gino, F., \& Galinsky, A. D. (2012). Vicarious dishonesty: When psychological closeness creates distance from one's moral compass. Organizational Behavior and Human Decision Processes, 119(1), 15-26.

Gino, F., Moore, D. A., \& Bazerman, M. H. (2009a). No harm, no foul: The outcome bias in ethical judgments. Harvard Business School NOM Working Paper (08-080). https://hbswk.hbs.edu/item/ no-harm-no-foul-the-outcome-bias-in-ethical-judgments. Accessed 24 July 2020.

Gino, F., Shu, L. L., \& Bazerman, M. H. (2010). Nameless + harmless=blameless: When seemingly irrelevant factors influence judgment of (un) ethical behavior. Organizational Behavior and Human Decision Processes, 111(2), 93-101.

Giroux, G. (2008). What went wrong? Accounting fraud and lessons from the recent scandals. Social Research, 75(4), 1205-1238.

Goldstein, N. J., Cialdini, R. B., \& Griskevicius, V. (2008). A room with a viewpoint: Using social norms to motivate environmental conservation in hotels. Journal of Consumer Research, 35(3), 472-482.

Gomes de Freitas, R. S., Thimoteo da Cunha, D., \& Stedefeldt, E. (2019). Food safety knowledge as gateway to cognitive illusions of food handlers and the different degrees of risk perception. Food Research International, 116, 126-134.

Green, R. M., \& Kane, K. (2014). The effective enforcement of HACCP based food safety management systems in the UK. Food Control, 37, 257-262.

Haberman, C. (2018). How an unsolved mystery changed the way we take pills. The New York Times, September 16. https://www.nytimes.com/2018/09/16/us/tylenol-acetaminophen-deaths.html. Accessed 22 April 2020.

Halabi, S. F., \& Lin, C.-F. (2017). Assessing the relative influence and efficacy of public and private food safety regulation regimes. Food and Drug Law Journal, 72(2), 262-294.

Harvard School of Public Health (HSPH). (2012). New insight from whole-genome sequencing of Europe's 2011 E. coli outbreaks. Phys.org, February 6. https://phys.org/news/2012-02-insightwhole-genome-sequencing-europe-coli.html. Accessed 19 October 2020. 
Hastie, R., \& Dawes, R. M. (2009). Rational choice in an uncertain world: The psychology of judgment and decision making. Thousand Oaks, CA: Sage Publications.

Hoelzer, K., Moreno Switt, A. I., Wiedmann, M., \& Boor, K. J. (2018). Emerging needs and opportunities in foodborne disease detection and prevention: From tools to people. Food Microbiology, 75, $65-71$.

Jacobs, S. B. (2009). Crises, Congress, and cognitive biases: A critical examination of food and drug legislation in the United States. Food and Drug Law Journal, 64, 599-629.

Jenni, K., \& Loewenstein, G. (1997). Explaining the identifiable victim effect. Journal of Risk and Uncertainty, 14(3), 235-257.

Johnson, D. (1986). The ethical dimension of acceptable risk in food safety. Agriculture and Human Values, 3, 171-179.

Jones, T. M. (1991). Ethical decision making by individuals in organizations: an issue-contingent model. Academy of Management Review, 16(2), 366-395.

Kahan, D. M., \& Posner, E. A. (1999). Shaming white-collar criminals: A proposal for reform of the federal sentencing guidelines. The Journal of Law and Economics, 42(S1), 365-392.

Kahneman, D., \& Tversky, A. (1979). Prospect theory: An analysis of decision under risk. Econometrica, 47, 263-291.

Kogut, T., \& Ritov, I. (2005). The "identified victim" effect: An identified group, or just a single individual? Journal of Behavioral Decision Making, 18(3), 157-167.

Konefal, J., Mascarenhas, M., \& Hatanaka, M. (2005). Governance in the global agro-food system: Backlighting the role of transnational supermarket chains. Agriculture and Human Values, 22, 291-302.

Kotsanopoulos, K. V., \& Arvanitoyannis, I. S. (2017). The role of auditing, food safety, and food quality standards in the food industry: A review. Comprehensive Reviews in Food Science and Food Safety, 16(5), 760-775.

Laforge, J. M. L., Anderson, C. R., \& McLachlan, S. M. (2017). Governments, grassroots, and the struggle for local food systems: Containing, coopting, contesting and collaborating. Agriculture Human Values, 34, 663-681.

Lee, H. K., Halim, H. A., Thong, K. L., \& Chai, L. C. (2017). Assessment of food safety knowledge, attitude, self-reported practices, and microbiological hand hygiene of food handlers. International Journal of Environmental Research and Public Health, 14(1), 55.

Loewenstein, G., Small, D. A., \& Strnad, J. (2006). Statistical, identifiable, and iconic victims. In E. J. McCaffery \& J. Slemrod (Eds.), Behavioral public finance (pp. 32-46). New York: Russell Sage Foundation.

Long, J. (2013a). Jensen Farms brothers have few defenses in cantaloupe prosecution. Natural Products Insider, October 7. https://www.naturalproductsinsider.com/litigation/jensen-farms-brothers-havefew-defenses-cantaloupe-prosecution. Accessed 22 April 2020.

Long, J. (2013b). Jensen Farms brothers meet with victims in listeria outbreak. Natural Products Insider, November 20. https:/www.naturalproductsinsider.com/litigation/jensen-farms-brothers-meet-victi ms-listeria-outbreak. Accessed 22 April 2020.

Lytton, T. D. (2019). Exposing private third-party food safety auditors to civil liability for negligence: harnessing private law norms to regulate private governance. European Review of Private Law, 27. http://ssrn.com/abstract=3216008. Accessed 29 April 2020.

Lytton, T. D., \& McAllister, L. K. (2014). Oversight in private food safety auditing: Addressing auditor conflict of interest. Wisconsin Law Review, 2, 289-335.

Ma, L. M., Fletcher, J., Mumford, J. D., Holt, J., \& Leach, A. W. (2017). Decision tool for assessing the likelihood of an intentional foodborne illness outbreak. In M. Gullino, J. Stack, J. Fletcher, \& J. Mumford (Eds.), Practical tools for plant and food biosecurity. Plant pathology in the 21 st century (Vol. 8, pp. 179-207). Dordrecht: Springer.

Marine, S. C., Martin, D. A., Adalja, A., Mathew, S., \& Everts, K. L. (2016). Effect of market channel, farm scale, and years in production on mid-Atlantic vegetable producers' knowledge and implementation of Good Agricultural Practices. Food Control, 59, 128-138.

Marklein, M. B. (2014). Cantaloupe farmers get no prison time in disease outbreak. USA Today, January 28. https://www.usatoday.com/story/news/nation/2014/01/28/sentencing-of-colorado-cantaloupe -farmers/4958671/. Accessed 22 April 2020.

McCarthy, R., \& Danley, S. (2020). Map: COVID-19 meat plant closures. Meat + Poultry, June 23. https ://www.meatpoultry.com/articles/22993-covid-19-meat-plant-map. Accessed 24 July 2020.

Moberg, D., \& Romar, E. (2003). WorldCom. https://www.scu.edu/ethics/focus-areas/business-ethics/ resources/worldcom/. Accessed 17 July 2020. 
Moore, D. A., Tetlock, P. E., Tanlu, L., \& Bazerman, M. H. (2006). Conflicts of interest and the case of auditor independence: Moral seduction and strategic issue cycling. Academy of Management Review, 31(1), 10-29.

Moss, M., \& Martin, A. (2009). Food problems elude private inspectors. New York Times, March 5. https://www.nytimes.com/2009/03/06/business/06food.html?_r=2\&scp=4\&sq=food\%20saf ety\&st=cse. Accessed 29 June 2020.

Onyango, B. M., Miljkovic, D., Hallman, W. K., Nganje, W. E., Condry, S. C., \& Cuite, C. L. (2007). Food Recalls and Food Safety Perceptions: The September 2006 Spinach Recall Case (working paper). Fargo, ND: Department of Agribusiness and Applied Economics, North Dakota State University.

Paharia, N., Kassam, K. S., Greene, J. D., \& Bazerman, M. H. (2009). Dirty work, clean hands: The moral psychology of indirect agency. Organizational Behavior and Human Decision Processes, 109(2), 134-141.

Parker, J. S., Wilson, R. S., LeJeune, J. T., \& Doohan, D. (2012). Including growers in the "food safety" conversation: Enhancing the design and implementation of food safety programming based on farm and marketing needs of fresh fruit and vegetable producers. Agriculture Human Values, 29, 303-319.

Powell, D. A., Erdozain, S., Dodd, C., Costa, R., Morley, K., \& Chapman, B. J. (2013). Audits and inspections are never enough: A critique to enhance food safety. Food Control, 30(2), 686-691.

Powell, D. A., Jacob, C. J., \& Chapman, B. J. (2011). Enhancing food safety culture to reduce rates of foodborne illness. Food Control, 22(6), 817-822.

Prevor, J. (2011). The cantaloupe crisis: audits, auditors and food safety. Perishable Pundit, October 23. http://www.perishablepundit.com/index.php?date=10/23/11. Accessed 17 July 2020.

Raafat, R. M., Chater, N., \& Frith, C. (2009). Herding in humans. Trends in Cognitive Sciences, 13(10), $420-428$.

Ranagek, J. M., Sparling, P. H., Crowe, H., Griffin, P. M., \& Swerdlow, D. L. (2005). Epidemiology of E. coli O157:H7 outbreaks, United States, 1982-2002. Emerging Infectious Diseases, 11(4), 603-609.

Reynolds, J., \& Dolasinski, M. J. (2019). Systematic review of industry food safety training topics \& modalities. Food Control, 105, 1-7.

Ritov, I., \& Baron, J. (1990). Reluctance to vaccinate: Omission bias and ambiguity. Journal of Behavioral Decision Making, 3(4), 263-277.

Shan, L., Wang, S., Wu, L., \& Tsai, F.-S. (2019). Cognitive biases of consumers' risk perception of foodborne diseases in China: examining anchoring effect. International Journal of Environmental Research and Public Health, 16(13), 2268.

Shapiro, J. T. (2013). Jensen Farms' fall underscores need for supply relation oversight in era of FSMA. Food Safety Magazine, November 5. https://www.foodsafetymagazine.com/enewsletter/jense n-farmse28099-fall-underscores-need-for-supply-relation-oversight-in-era-of-fsma/. Accessed 22 April 2020.

Skeel, D. A. (2001). Shaming in corporate law. University of Pennsylvania Law Review, 149(6), 1811-1868.

Small, D. A., \& Loewenstein, G. (2003). Helping a victim or helping the victim: Altruism and identifiability. Journal of Risk and Uncertainty, 26(1), 5-16.

Small, D. A., \& Loewenstein, G. (2005). The devil you know: The effects of identifiability on punishment. Journal of Behavioral Decision Making, 18(5), 311-318.

Sperling, D. (2010). Food law, ethics, and food safety regulation: roles, justifications, and expected limits. Journal of Agricultural and Environmental Ethics, 3, 267-278.

Spranca, M., Minsk, E., \& Baron, J. (1991). Omission and commission in judgment and choice. Journal of Experimental Social Psychology, 27(1), 76-105.

Steir, R. F. (2009). Third party audits: what the food industry really needs. Food Safety Magazine. https:// www.foodsafetymagazine.com/magazine-archive1/octobernovember-2009/third-party-audits-whatthe-food-industry-really-needs/. Accessed 29 July 2020.

Stuart, D., \& Worosz, M. R. (2012). Risk, anti-reflexivity, and ethical neutralization in industrial food processing. Agriculture and Human Values, 29, 287-301.

Stuart, D., \& Worosz, M. R. (2013). The myth of efficiency: technology and ethics in industrial food production. Journal of Agricultural and Environmental Ethics, 26, 131-156.

Sunstein, C. R. (2004). Moral heuristics and moral framing. Minnesota Law Review, 88, 1556-1597. 
Sykes, G. M., \& Matza, D. (1957). Techniques of neutralization: A theory of delinquency. American Sociological Review, 22(6), 664-670.

Taylor, M. R. (2011). Will the Food Safety Modernization Act help prevent outbreaks of foodborne illness? New England Journal of Medicine, 365, e18.

Tenbrunsel, A. E., Diekmann, K. A., Wade-Benzoni, K. A., \& Bazerman, M. H. (2010). The ethical mirage: A temporal explanation as to why we are not as ethical as we think we are. Research in Organizational Behavior, 30, 153-173.

Tenbrunsel, A. E., \& Messick, D. M. (2004). Ethical fading: The role of self-deception in unethical behavior. Social Justice Research, 17(2), 223-236.

Thaler, R. H., \& Sunstein, C. R. (2003). Libertarian paternalism. American Economic Review, 93, $175-179$

Tversky, A., \& Kahneman, D. (1974). Heuristics and biases: Judgement under uncertainty. Science, 185(4157), 1124-1130.

U.S. Department of Justice (USDoJ). (2013). Eric and Ryan Jensen plead guilty to all counts of introducing tainted cantaloupe into interstate commerce. Colorado. https://www.justice.gov/usao-co/pr/ eric-and-ryan-jensen-plead-guilty-all-counts-introducing-tainted-cantaloupe-interstate. Accessed 22 April 2020.

U.S. House of Representatives (USHR). (2012). Report on the investigation of the outbreak of listeria monocytogenes in cantaloupe at Jensen Farms. Washington, D.C. http://perma.cc/Y79W-A64S. Accessed 22 April 2020.

Vitell, S. J., \& Grove, S. J. (1987). Marketing ethics and the techniques of neutralization. Journal of Business Ethics, 6, 433-438.

Wall, P. G., \& Chen, J. (2018). Moving from risk communication to food information communication and consumer engagement. npj Science of Food, 2, 21.

Wang, M., Bai, L., Gong, S., \& Huang, L. (2020). Determinants of consumer food safety self-protection behavior-An analysis using grounded theory. Food Control, 113, 107198.

Watkins, M. D., \& Bazerman, M. H. (2003). Predictable surprises: The disasters you should have seen coming. Harvard Business Review, 81(3), 72-85.

World Bank. (2018). The safe food imperative: accelerating progress in low- and middle-income countries. Washington, DC: World Bank. https://www.worldbank.org/en/topic/agriculture/publication/ the-safe-food-imperative-accelerating-progress-in-low-and-middle-income-countries. Accessed 19 October 2020.

World Health Organization (WHO). (2012). Five keys to growing safer fruits and vegetables. Geneva: WHO. https://www.who.int/publications/i/item/five-keys-to-growing-safer-fruits-and-vegetables. Accessed 19 October 2020.

World Health Organization (WHO). (2018). WHO congratulates South Africa on the end of the world's largest listeriosis outbreak. Geneva: WHO. https://www.afro.who.int/news/who-congratulatessouth-africa-end-worlds-largest-listeriosis-outbreak. Accessed 19 October 2020.

World Health Organization (WHO). (2020). Food safety. Geneva: WHO. https://www.who.int/newsroom/fact-sheets/detail/food-safety. Accessed 19 October 2020.

Young, I., \& Waddell, L. (2016). Barriers and facilitators to safe food handling among consumers: A systematic review and thematic synthesis of qualitative research studies. PLoS ONE, 11(12), e0167695.

Publisher's Note Springer Nature remains neutral with regard to jurisdictional claims in published maps and institutional affiliations. 